\title{
El gobierno abierto como opción de política pública para el desarrollo en los gobiernos locales en México
}

\section{Open government as a public policy option for development for the development of local governments in Mexico}

DOI: $10.46932 /$ sfjdv3n1-047

Received in: Dec 30st, 2021

Accepted in: Jan 1th, 2022

\author{
Miguel Ángel Medina Romero ${ }^{1}$ \\ Universidad Michoacana de San Nicolás de Hidalgo (México) \\ E-mail: miguel.medina.romero@umich.mx \\ Raúl Alberto Rodríguez Alvarado ${ }^{2}$ \\ Universidad de Colima (México) \\ E-mail: rrodriguez43@ucol.mx
}

\section{RESUMEN}

En el presente documento se realiza una breve revisión conceptual del gobierno abierto, sus principios, así como su organización global y su fórmula institucionalizada. Se aborda, además, la instauración en México de este paradigma que involucra transparencia, participación ciudadana, colaboración y rendición de cuentas. Así, brevemente planteamos un conjunto de consideraciones para alcanzar el desarrollo desde los gobiernos locales, a partir de la concepción y la instauración de política pública del gobierno abierto en el nivel local, opción en la que la corresponsabilidad en una gobernanza participativa ocupa un destacado nivel de importancia.

Palabras clave: Gobierno abierto, política pública, desarrollo, gobierno local, transparencia, rendición de cuentas, participación ciudadana.

\begin{abstract}
This paper provides a brief conceptual review of open government, its principles, as well as its global organization and institutionalized formula. It also addresses the establishment in Mexico of this paradigm that involves transparency, citizen participation, collaboration and accountability. Thus, we briefly present a set of considerations to achieve development from local governments, based on the conception and implementation of open government public policy at the local level, an option in which co-responsibility in participatory governance occupies a prominent level of importance.
\end{abstract}

Keywords: open government, public policy, development, local government, transparency, accountability, citizen participation.

\footnotetext{
${ }^{1}$ Doctor en Derecho y Doctor en Ciencias Administrativas. Actualmente es profesor e investigador titular en la Facultad de Derecho y Ciencias Sociales y en el Centro de Investigaciones Jurídicas y Sociales de la Universidad Michoacana de San Nicolás de Hidalgo, en Morelia, Michoacán, México.

${ }^{2}$ Doctor en Políticas Públicas, Gobierno Local y Desarrollo. Actualmente es profesor e investigador en la Facultad de Economía de la Universidad de Colima, en Colima, Colima, México.
} 


\section{INTRODUCCIÓN}

El desarrollo de las sociedades contemporáneas, principalmente las occidentales, se ha verificado en el contexto de la nueva arquitectura económica, social y urbana que la globalización ha edificado a partir de los acuerdos de Bretton Woods de 1944, y que ha brindado ganancias a sus economías asociadas, permitiendo el desempeño de áreas y disciplinas promovidas por los organismos internacionales liderados por la Organización de las Naciones Unidas (ONU), así como el Banco Mundial (BM), el Fondo Monetario Internacional (FMI), el Fondo Internacional de Desarrollo Agrícola (FIDA), el Fondo Monetario Internacional (FMI), la Organización de las Naciones Unidas para el Desarrollo Industrial (ONUDI), la Organización de las Naciones Unidas para la Alimentación y la Agricultura (FAO), la Organización de las Naciones Unidas para la Educación, la Ciencia y la Cultura (UNESCO), la Organización Internacional del Trabajo (OIT) y la Organización Mundial de la Salud (OMS).

De esta dinámica colectiva, principalmente desde la ONU, ha evolucionado un esfuerzo intelectual de los comités de hombres y mujeres que lo conforman para desarrollar la idea universal de los derechos humanos, definiéndolos y promoviendo su defensa, de manera casi utópica, permeando en el desarrollo de casi todos los aspectos humanos. Y, aunque dicho esfuerzo ha sido acogido por organismos de cooperación internacional regionales y gobiernos nacionales alrededor del mundo incluyéndolos en sus legislaciones, ha sido en su instrumentación donde se ha abierto la brecha promovida por la desigualdad.

El Gobierno Abierto (GA), es uno de estos intelectuales y profundos esfuerzos para el diseño y construcción de un puente que permita unir los utópicos objetivos del desarrollo integral con nuestra heterogenia y polarizada realidad. El GA supone una construcción, primero teórica, de un modelo de gobierno que, con el uso de las herramientas de las tecnologías de la información -en la revolución 4.0gestiona y promueve el desarrollo en transparencia de recursos, procesos y decisiones, incorporando la participación ciudadana para discutir los temas, fijar los objetivos y llevarlos a la ejecución, aplicando métodos estadísticos que permitan medir la eficacia y eficiencia de los recursos empleados y sus impactos en la realidad. La intención del presente trabajo consiste en plantear un conjunto de consideraciones para alcanzar el desarrollo desde los gobiernos locales, a partir de la concepción y la instauración de política pública del gobierno abierto en el nivel local, considerando los casos de México -en el nivel nacional- y del Estado de Colima -en el nivel local-.

\section{DISEÑO CONCEPTUAL DEL GOBIERNO ABIERTO COMO PROMOTOR DEL DESARROLLO}

Desde finales del siglo XX, numerosos países vienen realizando esfuerzos para promover el Gobierno Abierto, con el aprovechamiento de las tecnologías de la información y las comunicaciones (TIC), para impulsar una administración más eficiente, eficaz y transparente. Mediante el ofrecimiento en 
línea de información a los ciudadanos, mecanismos de control de gestión, servicios, trámites y contratación estatal de bienes y servicios a través de las redes digitales, esta iniciativa avanza en el contexto de una economía mundial basada en la gestión del conocimiento.

El mejoramiento del desempeño del sector público, a través de la oferta de servicios en línea para la ciudadanía y el fortalecimiento de los elementos participativos, han impulsado la formulación de estrategias para lograr una administración con políticas públicas y programas gubernamentales eficientes que entreguen buenos resultados y sean más transparentes, eficaces y democráticos en su gestión. Así, basados en indicadores de gestión acordes con los objetivos estratégicos de cada institución, se fortalecen los modelos de gestión que privilegien los resultados sobre los procedimientos, como la integración de sistemas multisectoriales, transversales y sinérgicos para lograr la ejecución, monitoreo y evaluación de los procesos de cumplimiento de programas, proyectos y políticas públicas (Naser y Ramírez, 2014: 5).

Esta evolución gubernamental surgió de la capacidad y recursos limitados de los Estados, así como de una ciudadanía informada, exigente y con necesidades cambiantes que busca sean atendidas, promotora de la apertura de los gobiernos, y que toma partido en las decisiones y acciones que le involucran, canalizando esa intención hacia la construcción de gobiernos donde la colaboración, la participación y la transparencia son los ejes centrales en la elaboración de las políticas públicas. Las iniciativas de GA implican un cambio de paradigma en la gestión gubernamental que involucra la generación de canales de comunicación para trabajar con la sociedad y los individuos en vías de co-crear valor público, fusiona la utilización intensiva de las TIC, con modalidades de gestión, planificación y administración y en donde el sistema tradicional de gobernar se ve sustentado a partir de tres pilares fundamentales: (i) la transparencia en la acción, procesos y datos del gobierno, (ii) la colaboración al interior del gobierno y con las personas que permita generar nuevas ideas para resolver problemas sociales y la (iii) participación que busca implicar de forma activa y real a los ciudadanos en la formulación y ejecución de políticas (Naser \&Ramírez, 2014:6).

Aunque no existe una definición convencional del concepto de GA, hay cierto consenso en que se desarrolla como un nuevo enfoque relacional entre los gobernantes, las administraciones y la sociedad (Ramírez-Alujas, 2011b), cuyo alcance tiende a ser global, orientadas a transformar al sector público, su aparato administrativo, sus productos y las formas de interactuar con la sociedad a la que sirve con efectos de impacto global: (a) incremento de la conectividad, el advenimiento de la Web 2.0 y el empoderamiento ciudadano de plataformas tecnológicas de comunicación, (b) presiones ciudadanas por una mayor transparencia y rendición de cuentas, mejores espacios de participación y la emergencia de los nuevos movimientos sociales (c) consolidación de gobiernos relacionales y de la gobernanza entendidas como formas de conducción sociopolítica (Mayntz, 2000) ya no emergente, sino predominante de coordinación y gestión de los asuntos públicos y rendición de cuentas (Aguilar Villanueva, 2006). 
El gobierno abierto, de acuerdo con Cruz (2017: 5), se define como una filosofía políticoadministrativa de interacción sociopolítica, democrática más agregativo, para conformar un gobierno accesible, transparente y receptivo. El gobierno americano, en el "Transparency and Open Government" (U.S. Government, 2009) define a un gobierno abierto como un sistema de transparencia (opinión pública), de participación del público (formulación de políticas) y de colaboración (gobierno, organizaciones y empresas). La Open Government Partnership, pide cuatro valores al gobierno abierto: (1) transparencia: información abierta con estándares básicos de datos abiertos; (2) participación ciudadana: debate público que contribuyan al desarrollo de una gobernanza más responsiva, innovadora y efectiva; (3) rendición de cuentas: regulaciones y leyes en caso de las faltas de cumplimiento; y (4) tecnología e innovación: fomento de la innovación y la capacidad de los ciudadanos para usar las tecnologías.

El paradigma relacional-modo de gobernanza del gobierno abierto, según Lathrop y Ruma (2010), es la co-innovación con los ciudadanos con recursos transparentes para una organización integrada y que trabaja en red. Para Ramírez-Alujas (2011a), el GA es un modelo de relación entre los gobernantes, las administraciones y la sociedad: transparente, multidireccional, colaborativo y orientado a la participación de los ciudadanos. Igualmente, según Gutiérrez-Rubí (2011), el GA es una cultura comunicación, un modelo organizativo y la liberación del talento creativo con una tecnología social y relacional que impulsa y estimula una cultura de cambio en la concepción, gestión y prestación del servicio público. Además, según Ortiz de Zárate (2014), el GA es interacción sociopolítica, basado en la transparencia, la rendición de cuentas, la participación y la colaboración más dialogante, con mayor equilibrio corresponsable entre el poder de los gobiernos y de los gobernados. En términos de la Organización para la Cooperación y el Desarrollo Económicos (OCDE, 2006), son tres las características de una administración abierta: (1) transparencia: acciones e individuos responsables bajo el escrutinio público; (2) accesibilidad: que los servicios públicos y la información sobre los mismos sean fácilmente accesibles por los ciudadanos; y (3) receptividad: que sea capaz de responder a nuevas demandas, ideas y necesidades. En el mismo tenor, Noveck (2011) define el GA como una estrategia innovadora. El mismo término, para Calderón y Lorenzo (2010), constituye una conversación con los ciudadanos con el fin de oír lo que ellos dicen y solicitan, para tomar decisiones basadas en sus necesidades y preferencias, lo que facilita la colaboración de los ciudadanos y funcionarios en el desarrollo de los servicios se prestan, que comunica todo lo que deciden y hacen de forma abierta y transparente. Y, en la visión de Cabo (2013), un GA garantiza que el gobierno y los servicios públicos son administrados y operados eficazmente y al escrutinio público y a la supervisión de la sociedad (transparencia). Ello debe ir acompañado de la progresiva expansión de espacios de diálogo, participación y deliberación en conjunto con la ciudadanía, aprovechando el potencial y energías disponibles en vastos sectores de la sociedad y en el mercado. 
A partir de la revisión conceptual del GA aquí efectuada, se puede concluir que el GA es una filosofía político- administrativa, un conjunto de doctrinas con justificaciones relativamente coherentes acerca de quiénes, qué y cómo administrativos (Hood y Jackson, 1997), es decir, acerca de qué debe hacerse, y de quiénes y cómo deben hacerlo, a fin de atender a unos valores o principios determinados. Es una profunda reflexión colegiada, sobre cómo el diseño de un gobierno participativo puede promover el desarrollo a partir de 3 herramientas fundamentales que idealmente eliminan la corrupción: la transparencia de recursos, la participación ciudadana y la rendición de cuentas, que culmine en implantar sólidos marcos jurídicos, institucionales y políticos que rijan el acceso a la información, la consulta y la participación pública en la materia que contribuye a mejorar la política pública, a luchar contra la corrupción y a incrementar la confianza de la sociedad en la administración (OCDE, 2003).

Finalmente, la Alianza para el Gobierno Abierto (AGA) constituyó un esfuerzo global para ampliar la frontera en la mejora del desempeño y de la calidad de los gobiernos, promoviendo su proclividad a ser más transparentes, efectivos y que rindan cuentas. De este modo, esta iniciativa multilateral comenzada en septiembre de 2011 y formalizada en Naciones Unidas (Mendoza, 2013), se orientó a propiciar compromisos concretos desde los gobiernos para promover la transparencia, aumentar la participación ciudadana en el debate y en la decisión de los asuntos públicos, combatir la corrupción y aprovechar las nuevas tecnologías para robustecer la gobernanza democrática y la calidad de los servicios públicos. Actualmente, 75 países en el mundo forman parte de la AGA; 16 de ellos pertenecen a Latinoamérica; y 15 países de la agrupación ya cuentan con planes de acción y compromisos asumidos ${ }^{3}$ (Ramírez-Alujas y Dassen, 2012:49).

\section{EL GOBIERNO ABIERTO EN MÉXICO: RESEÑA DE LA ADOPCIÓN DE UN NUEVO PARADIGMA DE GOBIERNO}

Los orígenes del GA se pueden rastrear tanto en la "libertad de información" (freedom of information) como en los principios de gobierno abierto (Sandoval-Almazán, 2015). La idea cobra nueva fuerza con un decreto de 2009 del expresidente americano Barack Obama, a partir del cual se dan por sentadas las bases de un cambio de paradigma en las administraciones públicas del orbe (McDermott, 2010). En México, desde el 2002 comenzó una serie de transformaciones hacia la adopción del gobierno digital y de algunas prácticas del GA, como la transparencia gubernamental, actualizándose sus marcos teóricos e implementando cambios en la administración pública (Luna-Reyes, Gil-García y Sandoval-

\footnotetext{
${ }^{3}$ Los países de América Latina y el Caribe que cuentan actualmente con planes de acción en el marco de la AGA son: Argentina, Brasil, Chile, Colombia, Costa Rica, El Salvador, Guatemala, Honduras, México, Panamá, Paraguay, Perú, República Dominicana, Trinidad y Tobago, y Uruguay. Solamente Jamaica se encuentra todavía en el proceso de formulación y posterior formalización de su plan de acción nacional.
} 
Almazán, 2015; y Sandoval-Almazán, 2013). Sin embargo, los esfuerzos terminaron enfocándose más en la transparencia gubernamental que en la construcción de mecanismos para impulsar prácticas de gobierno abierto (Sandoval, 2015).

Así, en el año 2002 comenzó la actualización del marco legal para implementar políticas de transparencia en México, cuando el gobierno federal publicó el Programa Nacional de Combate a la Corrupción y Fomento a la Transparencia 2001-2006 (Diario Oficial de la Federación [DOF], 2002), creando el Acuerdo de la Secretaría de Gobernación y la Ley Federal de Transparencia y Acceso a la Información Pública Gubernamental (LFTAIPG). Esta normatividad estableció que las dependencias y entidades debían crear y mantener actualizado un sitio electrónico que integra información referida a las características esenciales de las dependencias, perfilando así lo que Quintanilla (2012) denomina etransparencia. Esta ley ha sido el origen de los portales gubernamentales de transparencia en México.

El concepto de gobierno abierto adquiere relevancia en México en 2011, a raíz de la creación de la Alianza para el Gobierno Abierto. Como se apuntó con antelación, se trató de una iniciativa multilateral, cuyo objetivo era crear gobiernos más eficaces y eficientes que respondan mejor a las necesidades de los ciudadanos y a los problemas públicos que enfrentan por medio de la transparencia, la rendición de cuentas, la participación ciudadana y la innovación (Naser, Ramírez-Alujas y Rosales, 2017). México fue uno de los 8 países fundadores de este esfuerzo conformado por naciones y organizaciones de la sociedad civil. $^{4}$

En el caso de México, el Primer Plan de Acción (2011-2012) surgió a partir de un plan de acción original y un plan de acción ampliado, donde se incluyeron las iniciativas del gobierno federal, a las que se adicionaron 36 propuestas de organizaciones de la sociedad civil para integrar el plan de acción ampliado. En este último se destaca la necesidad de fortalecer la coordinación entre el gobierno y las organizaciones de la sociedad civil para determinar acciones concretas y herramientas que hicieran posible su medición, con el objetivo de contribuir al cumplimiento transparente y total de los planes de acción ${ }^{5}$. El Segundo Plan de Acción (2013-2015) contiene 17 compromisos que, sumados a los 9 proyectos presentados por el gobierno de la República, buscaron atender 5 temas centrales: i) gobernanza de recursos naturales, ii) empoderamiento y participación ciudadana, iii) datos abiertos para el desarrollo, iv) presupuesto abierto y participativo y v) gobierno centrado en la ciudadanía. ${ }^{6}$

\footnotetext{
${ }^{4}$ Cada país miembro se compromete a diseñar e implementar, junto con la sociedad civil, un plan de acción nacional integrado por proyectos concretos que promuevan los principios de gobierno abierto durante un período de dos años. Véase [en línea] http://www.opengovpartnership.org/es/acerca-de.

5 Para conocer el informe completo del Primer Plan de Acción, véase [en línea] http://aga.ifai. $\mathrm{mx} /$ SitePages/EstamosHaciendo.aspx.

${ }^{6}$ Véase [en línea] http://gobabiertomx.org/alianza-mexico/.
} 
Así, en materia de GA, México se convirtió en el primer país en cumplir al $100 \%$ las metas establecidas. A partir de esta experiencia, en noviembre de 2015, se inició la elaboración del Tercer Plan de Acción, en el que se incluyeron: i) derechos humanos y fortalecimiento del Estado de derecho, ii) equidad de género, iii) Sistema Nacional Anticorrupción, iv) gobernanza de recursos naturales y cambio climático, v) pobreza y desigualdad y vi) servicios públicos (Naser, Ramírez-Alujas y Rosales, 2017:115). Además, México asumió la presidencia de la AGA en el marco del sexagésimo noveno período de sesiones de la Asamblea General de las Naciones Unidas, en septiembre de 2014. Con ello, México asumió el liderazgo de esta iniciativa por un período de un año, junto con un copresidente de la sociedad civil.

De igual manera, se consideró que, en las entidades federativas de México, un federalismo cooperativo es necesario si se pretende ingresar la iniciativa del GA en el plano subnacional y local, en términos de una viabilidad sustentable y exitosa. La evolución de un GA viene con la formación y ejecución de un federalismo cooperativo donde deviene imprescindible instrumentar e integrar de forma estratégica los modelos relacionales (Wrigth, 1997), los mecanismos de control de dinámicas entre gobiernos (Parrado, 2010), y los instrumentos colaborativos entre los mismos (Radin, 2007). Transitar de un federalismo centralizado hacia un federalismo más cooperativo, obliga el abordaje desde los tres modelos de Wright (1997) que sugieren que el federalismo cooperativo ideal para un GA que reconoce un modelo de autoridad superpuesta e interdependiente en la atención de los asuntos públicos. Esto termina por vincular a los órdenes de gobierno frente a escenarios de alta dosis de negociación, en contextos de reciprocidad e intercambio, para aplicar instrumentos colaborativos de corte intergubernamental.

En la Cumbre de la Alianza por un Gobierno Abierto de 2012, México presentó un documento que avala la intención de los gobernadores de sus entidades federativas por suscribir los términos que hagan posible reproducir esta iniciativa internacional en los estados y municipios de México en aras de articular un conjunto de instrumentos colaborativos, que aumenten las posibilidades de relacionarse exitosamente en los tres niveles de gobierno hacia una concepción federal más cooperativa, con agendas de asuntos públicos, donde la colaboración toma relevancia y significancia.

En 2014, se proveyó de autonomía constitucional al Instituto Federal de Acceso a la Información Pública y Protección de Datos (IFAI), hoy Instituto Nacional de Transparencia, Acceso a la Información Pública y Protección de Datos Personales (INAI), constituyéndose en un organismo autónomo con personalidad jurídica y patrimonio propio, con plena autonomía técnica, de gestión, capacidad para decidir sobre el ejercicio de su presupuesto y determinar su organización interna, responsable de garantizar el cumplimiento del derecho de acceso a la información pública y a la protección de datos personales en posesión de los sujetos obligados, estableciéndose, así, una nueva etapa en el sistema a de evolución de transparencia y acceso a la información en el país. 


\section{EL GOBIERNO ABIERTO EN COLIMA (MÉXICO): UNA EXPERIENCIA DE SU} IMPLEMENTACIÓN

El concepto del gobierno abierto es susceptible, también, de incorporarse al ámbito de la gestión pública del desarrollo local. En consideración de ello, el objetivo del presente apartado de esta participación consiste en abordar la instauración de política pública del GA en el nivel local, a partir de la exposición de la experiencia del estado de Colima en México.

De acuerdo con la revisión de la literatura, el nivel local -respecto a la dimensión nacional- es el que más retraso muestra respecto a la materialización del concepto del GA. Y, particularmente, el municipio - expresión de la dimensión local- es el que más rezagos presenta en la aplicación de tecnología, así como posee los más bajos niveles de transparencia, colaboración y participación ciudadana. De acuerdo con el Instituto Nacional de Estadística, Geografía (INEGI, 2015), de 2,441 municipios solo 366 cuentan con algún ordenamiento sobre participación ciudadana. Las reglamentaciones son exiguas en los municipios; únicamente 531 han regulado la transparencia, 143 el combate a la corrupción y 366 la participación ciudadana. Estos datos manifiestan el contrasentido de trabajar el GA únicamente a nivel federal, puesto que se requiere de un esfuerzo unificado en los tres órdenes de gobierno para disminuir los altos niveles de corrupción que aquejan al país (Meléndez y Vázquez, 2017). Según la revista Política Digital, en el año 2010, solo 1,204 municipios cuentan con portal electrónico, es decir, un 45\% del total; el 36\% de los municipios evaluados incumplen con la transparencia; y el 39\% de los portales revisados carecen de al menos un elemento de retroalimentación o participación ciudadana. Por tanto, es fundamental dotar a los municipios de sitios electrónicos informativos, interactivos y transaccionales, que incluyan elementos de participación y transparencia, es decir sitios verdaderamente 2.0. Estudios más recientes tienen como característica no haber considerado al total de municipios con portal electrónico (Meléndez y Vázquez, 2017).

A nivel local, el estado de Colima se encuentra ubicado en la vertiente del Océano Pacifico, en la parte media y al extremo oeste de la República Mexicana. La población total es de 711,235 de los cuales 360,444 son mujeres y 350,791 son hombres. La importancia de los servicios va de la mano con el papel del Puerto de Manzanillo, en la economía estatal: es el mayor puerto de México y el cuarto más grande de América Latina. El sector servicios agrupa 26,244 unidades económicas, lo que representa 89.7\% del total. Estas generan una producción bruta de 23,738 millones de pesos (mdp), corresponde al 58.1\% del total y ocupa a 111,315 personas que producen el $70.4 \%$ del valor actual de costos variables (VACV) del Estado, equivalente a 13,293 mdp. El dinamismo en el comercio, el transporte, la logística, el almacenamiento, los servicios inmobiliarios y de alquiler de bienes inmuebles e intangibles, constituyen el $61.5 \%$ del Producto Interno Bruto (PIB) de este sector, por lo que la logística tiene una gran relevancia 
en este proceso y genera un efecto de atracción del desarrollo del sector privado y del crecimiento en el resto de los actores económicos de la región (De Colima, 2016).

El modelo colimense de gobierno abierto, transitó por el gobierno electrónico y tiene sus orígenes en la voluntad modernizadora que se gestó desde 1983 en la Universidad de Colima (UC) con la creación del sistema de administración bibliotecaria, donde la estrategia fue que todo el acervo bibliográfico debía procesarse automáticamente y, para ello, se creó el Sistema Integral Automatizado de Bibliotecas de la Universidad de Colima (SIABUC). De la misma manera, se fueron incorporando otras acciones como el programa de microfilmación, la creación de bases de datos en micro-isis, el desarrollo de sucesivas versiones mejoradas de SIABUC y la creación de un disco compacto (Hernández, 2006).

Para 1989, el primer disco compacto de la UC se produjo en la Biblioteca Regional de Medicina (BIROME) de la Organización Panamericana de la Salud (OPS), ubicada en Brasil. En 1990 se creó el Centro Nacional Editor de Discos Compactos (CENEDIC) para dotar a Colima de la infraestructura necesaria para editarlos en la UC. Así, durante 1993 se editaron discos compactos para una gran variedad de instituciones o empresas (Hernández, 2006). En noviembre de 1996, el rector de la UC y promotor de la modernización tecnológica en la entidad, Fernando Moreno Peña es electo gobernador constitucional de Colima, cargo del que tomó posesión en octubre de 1997 y el 28 de abril de 1998 expidió el decreto que aprueba el Plan Estatal de Desarrollo 1998-2003, donde el capítulo VII se intitula Nueva Cultura de la Gestión Pública, manifiestando la influencia de Crozier, señalando que: "La administración pública moderna, no quiere más poder sino pasar el poder a los ciudadanos, no estandariza al público sino que se vuelvue hacia servicios especializados, no le interesa el secreto, sino la transparencia en el ejercicio de sus funciones, no favorece los equilibrios sino la dinámica; le interesa sobre todo los resultados más que los procedimientos y acepta la evaluación oportuna como parte de esa nueva ética y cultura". Así, desde el gobierno estatal se adoptó la necesidad de construir una nueva cultura de la gestión pública en donde la participación ciudadana con el gobierno sea práctica permanente en la definición, desarrollo y evaluación de la gestión pública, y en el Plan Estatal de Desarrollo se reconoció que los recursos humanos son el capital fundamental para desarrollar una nueva cultura de la gestión pública; y el capital humano y la voluntad política del gobierno del Estado son los elementos principales para modernizar el funcionamiento administrativo y de servicios de la estructura gubernamental. En el Plan Estatal de Desarrollo 1998-2003, aparece el binomio conceptual de "La nueva cultura de la gestión pública" con "modernización". La combinación de ambos conceptos daría una nueva fisonomía administrativa y pública al gobierno estatal.

En el Colima contemporáneo, con fecha 13 de diciembre de 2018, el gobierno del Estado firmó un convenio con la Alianza para el Gobierno Abierto y la Ley General de Transparencia y Acceso a la Información Pública; el INAI, organizaciones de la sociedad civil, instituciones de distintos órdenes de gobierno y el organismo garante del Estado de Colima. El documento reconoce un convencimiento mutuo 
para contribuir a la construcción de un nuevo modelo de gobernanza que consolide a la transparencia, la rendición de cuentas, la participación ciudadana y la co-creación gubernamental como catalizadores de otros de otros derechos; del combate a la corrupción, del empoderamiento ciudadano y de la mejora en la gestión gubernamental. Que los actores de las entidades federativas y municipios por su cercanía con la población pueden influir con mayor oportunidad en el incremento de su calidad de vida, por lo que el tránsito a un GA debe gestarse desde la base del Estado, y debe constituirse como el puente de diálogo y un espacio de construcción de concesos entre a sociedad y el gobierno para dar salida conjunta a los retos y desafíos de las democracias contemporáneas. Que la transparencia y la rendición de cuentas deben constituirse como ejes fundamentales de las prácticas cotidianas de todos los poderes, órdenes y niveles de gobierno; y que las TIC son el medio innovador para la instrumentación de las iniciativas gubernamentales democráticas que se socializan en los medios adecuados para que conocimiento de la población.

Posteriormente, el 28 de febrero, 2020, se llevó a cabo la instalación del Secretariado Técnico Local del Ejercicio de Gobierno Abierto en el Estado de Colima, conformado por el Instituto de Transparencia, Acceso a la Información Pública y Protección de Datos del Estado de Colima (INFOCOL), entes públicos y el Órgano Superior de Auditoría y Fiscalización Gubernamental (OSAFIG) y la organización no gubernamental (ONG) “¿Cómo Vamos?”, así como en el marco de las asociaciones civiles, junto con los representantes de la Cámara Nacional de la Industria de la Transformación (CANACINTRA) -filial Colima-, la Federación de Colegios, Barras y Asociaciones de Abogados del Estado de Colima, como representantes de las sociedades civiles. En el informe de labores 2019 del INFOCOL se informó que durante el 2018 se recibieron 3,787 solicitudes de acceso a la información pública; mientras que en el 2019 se registró un total de 5,213, esto significa que la cifra de solicitudes se incrementó en $27.3 \%$. El 85\% de las solicitudes recibidas se contestaron en sentido positivo, mientras que solo un $3 \%$, se respondieron de manera negativa, y el $12 \%$ restante fueron desechadas por motivos diversos, toda vez que por su propia naturaleza, no podían considerarse como solicitudes de información, como en el ejercicio de derecho de petición, una consulta, o en su caso se marcó incompetencia sugiriendo al solicitante dirigirla al sujeto obligado que posiblemente genere, posea o resguarde información, de conformidad a las funciones que realiza.

Durante el 2018, se registraron 8’554,519 visitas a los portales de transparencia que conforman el padrón de sujetos obligados, mientras que, en 2019, el número disminuyo a 3’634,015 visitas; es decir, $42 \%$ respecto a 2018. De los organismos que rindieron cuentas, solo el 17\% cumplió con la totalidad de sus obligaciones en materia de transparencia; el 24\%, si bien no cumplió con el 100\%, si solvento algunas observaciones que le permitieron elevar el porcentaje inicial; sin embargo, el 59\% de los sujetos obligados 
evaluados, no cumplió en una primera etapa con el porcentaje máximo y, además no solventó las observaciones realizadas, en el término otorgado para ello.

\section{CONSIDERACIONES FINALES}

La formulación teórica del concepto de gobierno abierto ha permitido guiar su conformación institucionalizada en el desarrollo de un movimiento global, que nos llega desde una agencia de cooperación internacional, con poder coadyuvante y vinculante, es decir, con la capacidad de incidir en la realidad por medio de la firma de tratados internacionales, que implican compromisos que surten jurisdicción en México, volviendo imperativa su implementación. Este esfuerzo busca blindar al gobierno de ineficacias, al transformarlo en un organismo vivo, que convive con la ciudadanía en un diálogo franco y permanente, transparente y fructificante, que genera políticas públicas que buscan resolver los problemas nodales de la sociedad.

Esta iniciativa multilateral arribó a México y, progresivamente, se disemina por sus entidades federativas y, así, llegó a Colima, en un primer plano del nivel local, y se orienta a transformar las leyes, buscando el resguardo de los derechos humanos en la política gubernamental, principalmente la ejecutiva. En México -en el plano federal-, la experiencia ha sido positiva en tanto se ha efectuado la adecuación y el cumplimiento de las normas de manera ortodoxa; y en el caso del estado de Colima, el movimiento comenzó desde 1983 en el contexto de la vinculación universidad-gobierno para modernizar a la sociedad, a partir de la promoción de la transparencia, la participación y los mecanismos de rendición de cuentas. En la actualidad, la asimilación del GA en Colima se ha concretado en la materialización de un complejo institucional, de leyes y reglamentos que dan vida al cambio de paradigma en la dinámica local en torno al gobierno abierto.

Sin embargo, en la práctica sigue existiendo una barrera, no por menos visible y menos infranqueable, ya que los gobiernos aún carecen, y tal vez de manera agudizada, de un diálogo permanente que abone a la resolución de los grandes temas del desarrollo local vinculados con la seguridad, la justicia social y la economía; o, incluso, los medianamente complicados como los relacionados con la competitividad e internacionalización. Así, ante estas circunstancias, la sociedad reduce su nivel de confianza en las instituciones y en sus gobiernos. Por ello, resulta imperativo, más que nunca, continuar fomentando y fortaleciendo la promoción de la transparencia, la participación, la colaboración y la rendición de cuentas en la dinámica de la acción gubernamental que, lejos de ser elementos que desorienten el camino, son elementos en los que hace falta trabajar y poner énfasis para su deseable funcionamiento en beneficio de las sociedades. El GA, por tanto, se encuentra con utilidad vigente y, en tanto enfoque de decisiones de política pública, resulta pertinente; y más aún, si se consideran las actuales condiciones de nuestras vidas enmarcadas en la emergencia sanitaria causada por Covid-19 (Ríos- 
Campos, Ríos, Camacho, Maldonado, Ávalos, Jurado Carrasco y Campoverde, 2021), circunstancia que requiere la participación, el esfuerzo y el concurso de todos. 


\section{REFERENCIAS}

Aguilar Villanueva, L. (2008). Gobernanza y gestión pública. México: Fondo de Cultura Económica.

Cabo, C. (2013), "Gobierno abierto: de la transparencia a la inteligencia cívica". En: Hoffman, A., A. V. Ramírez Alujas, y J. A. Bojórquez Pereznieto. La promesa del gobierno abierto. En: [http://goo.gl/50KMMa].

Calderón, C. y E. Lorenzo. (2010). Open Government: Gobierno Abierto. España: Algón Editores.

Cámara de Diputados del H. Congreso de la Unión. (1976). Ley Orgánica de la Administración Pública Federal. México. En: [http://www.diputados.gob.mx/LeyesBiblio/pdf/153_22012 0.pdf]

(2002). Ley Federal de Transparencia y Acceso a la Información Pública Gubernamental. México. En: [http://www.inea.gob.mx/ transparencia/pdf/LFTAIPG.pdf]

Cámara de Diputados del H. Congreso de la Unión. (2015). Ley General de Transparencia y Acceso a la Información Pública. México. En: [http://www.diputados.gob.mx/LeyesBiblio/pdf/LGTAIP_130820.pdf]

(2010). Ley Federal de Protección de Datos Personales en Posesión de los Particulares. México. En: [http://www.diputados.gob.mx/ LeyesBiblio/pdf/LFPDPPP.pdf]

(2016a). Ley de Fiscalización y Rendición de Cuentas de la Federación. México. En: [http://www.diputados.gob.mx/LeyesBiblio /pdf/LFRCF.pdf]

--------. (2016b). Ley General de Responsabilidades Administrativas. México. En: [http://www.diputados.gob.mx/LeyesBiblio/pdf/LGRA_ 130420.pdf]

---------. (2016c). Ley General del Sistema Nacional Anticorrupción. México. En: [http://www.diputados.gob.mx/LeyesBiblio/pdf/LGSNA.pdf]

(2017). Ley General de Protección de Datos Personales en Posesión de Sujetos Obligados. México. En: [http://www.dof.gob.mx/nota_

Cruz-Rubio, C. N. (2015). ¿Qué es (y qué no es) gobierno abierto? Una discusión conceptual. En: EUNOMÍA. Revista en Cultura de la Legalidad. No. 8. Marzo-agosto. Pp. 37-53. España: Universidad Carlos II de Madrid.

Diario Oficial de la Federación. (2002a). Ley Federal de Transparencia y Acceso a la Información Pública Gubernamental. 11 de junio. Última reforma publicada el 6 de junio de 2006. México.

(2002b). Programa Nacional de Combate a la Corrupción y Fomento a la Transparencia y el Desarrollo Administrativo 2001-2006. 22 de abril. México.

Gutiérrez-Rubí, A. (2011). “Open Government” y crisis económica". En: Diario Cinco Días. 25 de enero. México. 
Hernández Chacón, G. (2006). La modernización de la administración pública: el gobierno electrónico del estado de Colima (2001-2004). Tesis de maestría. México: Centro de Investigación y Docencia Económicas. En: [http://hdl.handle.net/11651/1558].

Hood, C.C. y Jackson, M. (1997). La argumentación administrativa. México: Fondo de Cultura Económica.

Instituto Nacional de Estadística y Geografía (2016). Encuesta Nacional de Acceso a la Información Pública y Protección de Datos Personales. En: [http://tinyurl.com/yba3n4vp].

Lathrop, D. y L. Ruma (2010). Open Government: collaboration, transparency and participation in practice. Sebastopol, O’Reilly Editors.

Mayntz, R. (1998). New challenges to governance theory. Jean Monet Chair Papers. $\mathrm{N}^{\mathrm{o}}$ 50. Florencia.

McDermott, P. (2010). Building open government. Government Information Quarterly. 27(4), 401-413. En: [https://doi.org/10.1016/j. giq.2010.07.002].

Meléndez, C. C., y Vázquez, A. Z. (2017). "Municipios y gobierno abierto, más allá del gobierno electrónico". Revista Opera. No. 21. Pp. 55-77.

Mendoza, R. E. V. (2013). "El federalismo cooperativo como factor catalizador de un Gobierno Abierto". En: Revista Mexicana de Ciencias Políticas y Sociales. 58 (219). Pp. 19-44.

Naser, A. y Á. Ramírez-Alujas. (2014). Plan de gobierno abierto: una hoja de ruta para los gobiernos de la región. Serie Manuales. No 81. (LC/L.3802; LC/IP/L.333). Chile: Comisión Económica para América Latina y el Caribe.

Noveck, B. S. (2009). Wiki Government. How Technology can Make Government Better, Democracy Stronger, and Citizens More Powerful. U.S.A.: Brooking Institution.

Obama, B. (2009). Memorándum on Transparency and Open Government (OGD), The Excutive Office of the President of United States of America. U.S.A. En: [http://whitehouse.gov/the_press_o ce/ TransparencyandOpenGovernment].

Organization for Economic Cooperation and Development. (2003). Open Gobernment: Fostering Dialogue with Civil Society. OECD.

Ortiz De Zárate, A. (2014). Debate ¿Cómo definimos Gobierno abierto? En: [http://goo.gl/sklRmC]. Parrado, S. (2010). "The role of Spanish Central Government in a Multi-Level State". En: International Review of Administrative Sciences. Pp 469-488. England.

Radin, Beryl, (2007) “The Instruments of Intergovernmental Management”. En: Peters, B. Guy y P. Jon (eds.), Handbook of Public Administration. Pp. 365-376. England: SAGE.

Ramírez-Alujas, A.V. (2011a). "Gobierno abierto y modernización de la gestión pública: tendencias actuales y el (inevitable) camino que viene. Reflexiones seminales". En: Revista Enfoques. Vol. IX. Núm. 15. Pp. 99-125. Chile: Pontificia Universidad Católica de Chile. 
Ramírez-Alujas, A.V. (2011b). Gobierno Abierto, Servicios Públicos 2.0 y Ciudadanía Digital: Notas para una nueva agenda de modernización de la gestión pública en Iberoamérica. España: Grupo de Investigación en Gobierno, Administración y Políticas Públicas. Disponible. En: [http://goo.gl/CWsN3r].

Ramírez-Alujas, A.V. y N. Dassen. (2014). Vientos de cambio: El avance de las políticas de gobierno abierto en América Latina y el Caribe. U.S.A.: Banco Interamericano de Desarrollo. En: [http://goo.gl/xucHm6].

Ríos-Campos, Ríos, Camacho, Maldonado, Ávalos, Jurado Carrasco y Campoverde. (2021). Covid-19 and universities in Latin America. South Florida Journal of Development. 2(1). Pp. 577-585. DOI: 10.46932/sfjdv2n1-041.

Sandoval-Almazán, R. (2015). "Gobierno abierto y transparencia: construyendo un marco conceptual". En: Convergencia. Revista de Ciencias Sociales. 22(68). Pp. 203- 227. México: Universidad Autónoma del Estado de México. En: [https://www.redalyc.org/pdf/105/10536227008.pdf].

U.S.A. Government. (2009). Transparency and Open Government: Memorandum for the Heads of Executive Departments and Agencies. U.S.A. En: [http://goo.gl/ilauWr].

Wright, D. S. (1997). Para entender las relaciones intergubernamentales. México: Fondo de Cultura Económica. 